\title{
RECOMMENDATIONS
}

\section{Reducing childhood pedestrian injuries}

Injury Prevention 2002;8(Suppl I):i9-i 10

\section{Goal}

To enhance the wellbeing and safety of children by

(1) reducing their risk of injury while walking;

(2) increasing their physical activity level; and

(3) creating a more pedestrian-friendly environment.

\section{RECOMMENDATION \# 1}

Enhance public awareness about the need for improved safety for child pedestrians while promoting the health and environmental benefits of walking

Create coordinated national, state, and local public information campaigns that increase public awareness and understanding of:

(1) The interdependent relationship among personal health, safety, community livability, and environmental protection.

(2) Pedestrians as road users who, like motorists and bicyclists, need to be safe in traffic.

(3) The manner and degree to which engineering solutions can enhance pedestrian safety (for example, traffic calming, separation of pedestrians from motor vehicle traffic, better crosswalk controls).

(4) The usefulness and cost effectiveness of traffic law enforcement.

\section{RECOMMENDATION \#2}

Modify the behavior and attitudes of both pedestrians and drivers to improve sharing of the road

(1) Develop and encourage strategies that improve sharing the road, and increase mutual respect of pedestrians and motorists by teaching both groups the rules of the road.

(2) Help the public understand the degree to which excessive speed increases stopping distances and thus increases the risk of pedestrian death.

(3) Encourage the public to support enforcement of posted speed limits (especially in school zones and residential areas), laws that prohibit passing of school buses, and yield-to-pedestrian laws. Support the development and use of innovative technologies, such as red light cameras to help enforce traffic laws.

(4) Develop, evaluate, and disseminate programs to educate parents and drivers about children's abilities and limitations as pedestrians in traffic. These programs should take into account different parenting styles and abilities. Encourage parents to supervise their children in traffic and teach their children age appropriate pedestrian safety rules.

\section{RECOMMENDATION \#3}

Modify the physical environment to better support pedestrian traffic

(1) At the national level:

- Establish transportation policies that encourage local communities to integrate pedestrian access and safety into every phase of transportation planning.

- Foster collaboration among federal agencies and national professional groups to help develop and promote public policy that leverages resources to achieve the most effective programs without duplicating efforts.

- Develop road construction standards that are more conducive to safe walking.

- Compile and disseminate local "best practices" that foster pedestrian safety, especially those that emphasize the use of low cost solutions and new technologies.

- Help teach traffic engineers and engineering students how to retrofit streets and roads to make them safer. Develop and disseminate curricula, sponsor professional conferences, and assist with continuing education.

(2) At the state and local levels:

- Encourage state and local officials to revise laws, ordinances, and practices to promote the construction of sidewalks and traffic calming measures, such as roundabouts, speed humps, and other road designs.

- Encourage city planners, engineers, real estate developers, and landscape architects to consider pedestrian safety-particularly for children and persons with disabilities-when designing new communities or modify existing ones.

- Encourage local officials, designers, and planners to enhance pedestrian accessibility and safety when building or remodeling schools, recreational sites, and businesses.

\section{RECOMMENDATION \#4}

Develop and conduct effective safe walking programs

(1) Ensure that programs to prevent child pedestrian injuries receive public and private program support sufficient to provide programs in all states. This may require corporate and Congressional champions and a national spokesperson.

(2) Encourage federal agencies responsible for road safety to make available effective pedestrian safety training activities for children. Encourage federal, state, and local departments of education to establish safe routes to school.

(3) Encourage states to develop statewide pedestrian safety plans that reflect community needs. 
Encourage each state department of transportation to establish and adequately staff a pedestrian safety office to coordinate and conduct training programs, conduct public information and education campaigns, and develop local programs throughout the state.

(4) At the community level, create multidisciplinary coalitions to develop programs that emphasize safety aspects and the health and environmental benefits of walking. Encourage parents, teachers, school administrators, pediatricians, and other child care providers to identify and creatively solve local pedestrian safety problems. Such coalitions should seek to enroll non-traditional partners.

\section{RECOMMENDATION \#5}

Conduct research to address gaps in knowledge and to translate research findings into effective programs and public policy

(1) Evaluate existing childhood pedestrian safety programs by using a systematic review process to determine which ones are effective and deserve widespread replication. Such programs include:

- Educational programs, such as Safe Routes to School, Walking School Bus, Willie Whistle, Keep on Looking, and others designed to reduce dart-outs and help children cross streets safely.

- Traffic calming strategies, such as roundabouts, speed humps, and other measures.

- Enforcement strategies, such as red light cameras and stricter ticketing of drivers who illegally pass school buses.

(2) Where sufficient data do not exist, use randomized controlled trials where feasible to measure intervention effectiveness.

(3) Conduct research to determine the cost effectiveness of promising programs.

(4) Fund research that links pedestrian safety to physical activity and a healthier environment.
(5) Identify behavioral indicators to help determine when a child is ready to cross the street independently. Assess the chronologic and developmental age, skill patterns, and teachable moments when children are most receptive to interventions.

(6) Determine what level of supervision children need at various levels of cognitive, social, skill, and behavioral development. Establish appropriate standards for such supervision.

(7) Develop, test, and evaluate programs that use teens to mentor young children in pedestrian safety.

\section{RECOMMENDATION \#6}

Conduct surveillance to measure children's pedestrian injury rates, quantify the amount of walking children normally do, and identify risk factors for injury

(1) Identify and validate useful indirect measures that predict the occurrence of a child pedestrian injury. Use these to monitor program effectiveness.

(2) Develop and test community indicators of the prevalence of walking for transportation, the public's beliefs about the benefits and risks of walking, and the existence of environmental and social risks of walking.

(3) Define children's exposure to risk of pedestrian injury that includes, but is not limited to, factors related to the time the child spends in the street; traffic density, speed, and complexity; and road features such as the number of lanes and existence of marked or signed crosswalks. Develop and implement methods of collecting data on such exposure.

(4) Develop local risk factor surveillance systems to monitor how and why child pedestrians are injured, and to identify the environmental and behavioral modifications that could have prevented such injury. Establish linkages to other data sources, particularly emergency department data and police crash reports. 